\title{
Potassium Ion Concentration Alters Glucagon Secretion Independently of Insulin Secretion in the Isolated Rat Pancreas
}

\author{
S. S. Smith, S. J. Bhathena, S. D. Wilkins and L. Recant \\ Veterans Administration Medical Center, Washington, DC, USA
}

Summary. In the arginine-stimulated perfused rat pancreas, elevated concentrations of potassium ion inhibited glucagon secretion while stimulating the secretion of insulin. Decreased potassium ion produced the reverse effect. The observed inverse correlation between changes in insulin and glucagon secretion $(r=-0.64 ; p<0.001)$ was suggestive of local interactions between islet hormones, and prompted us to determine whether potassium-induced changes in glucagon secretion were dependent upon concurrent changes in insulin release. We found that when insulin secretion was greatly suppressed, either through acute induction of diabetes with streptozotocin or by utilization of a glucose-free perfusate, no qualitative differences in glucagon responsiveness to altered potassium ion were evident, although the amplitude of these glucagon changes was enhanced. Similarly, when exogenous insulin $(20,000 \mathrm{mU} / 1)$ was added to the perfusate in order to render potassium-induced changes in endogenous insulin secretion insignificant, glucagon responsiveness to altered potassium ion was maintained. Exogenous insulin alone had no effect on arginine-stimulated glucagon secretion. We conclude that any indirect effects of potassium ion on arginine-stimulated glucagon secretion are not mediated by insulin, but could be related to changes in somatostatin secretion.

Key words: Potassium ion, pancreas perfusion, glucagon, insulin, experimental diabetes mellitus, insulin clamp.

Previous studies have demonstrated a stimulatory action of elevated potassium ion concentration $\left[\mathrm{K}^{+}\right]$on insulin secretion both in vivo [1] and in vitro [2-4]. It is suggested that this effect is due to a direct action of the ion on the pancreatic islet B cell, inasmuch as potassium has been shown to cause depolarization of the $B$ cell [5] and to reverse the inhibition of insulin secretion by somatostatin [3]. Furthermore, potassiuminduced stimulation of insulin secretion appears to occur regardless of the presence or absence of concurrent glucose or arginine stimulation [4].

Glucagon responsiveness to elevated $\left[\mathrm{K}^{+}\right]$, however, presents a more complicated issue. We have shown that elevated $\left[\mathrm{K}^{+}\right]$in the perfused rat pancreas inhibits arginine-stimulated glucagon release [3]. While confirming these findings in the arginine-stimulated model, Epstein et al. have also shown increased release of glucagon by $\mathrm{K}^{+}$in the absence of arginine stimulation [4]. These authors have, in addition, presented evidence to suggest that such stimulation may be due to a direct, depolarizing effect of the ion on the A cell. If true, then one might rationally propose that $\mathrm{K}^{+}$-induced inhibition of glucagon release in the presence of arginine represents an indirect effect of the ion, most probably mediated through the local interaction of other islet hormones with the A cell.

With these considerations in mind, we have undertaken additional studies to define more carefully the effects of both high and low $\left[\mathrm{K}^{+}\right]$on glucagon secretion from the arginine-stimulated perfused rat pancreas. We have investigated the relationship of these effects to simultaneous changes in insulin secretion, in an attempt to determine whether such changes are, indeed, prerequisite to $\mathrm{K}^{+}$-induced changes in glucagon secretion.

\section{Materials and Methods}

Fed, male Sprague-Dawley rats weighing 250-300g (Flow Animal Laboratories, Dublin, Virginia, USA) were anaesthetised with sodium amobarbital (Amytal, Lilly), followed by surgical isolation of the pancreas-stomach-duodenum preparation according to the method of Curry et al. [6]. Perfusions were carried out as described previously [3], using Krebs-Henseleit bicarbonate buffer ( $\mathrm{pH} 7.4$ ) containing 3\% dextran T-40 (Pharmacia Fine Chemicals, Uppsala, Sweden), 1\% human albumin (Cutter Laboratories, Berkeley, Cali- 


\section{GLUCAGON}
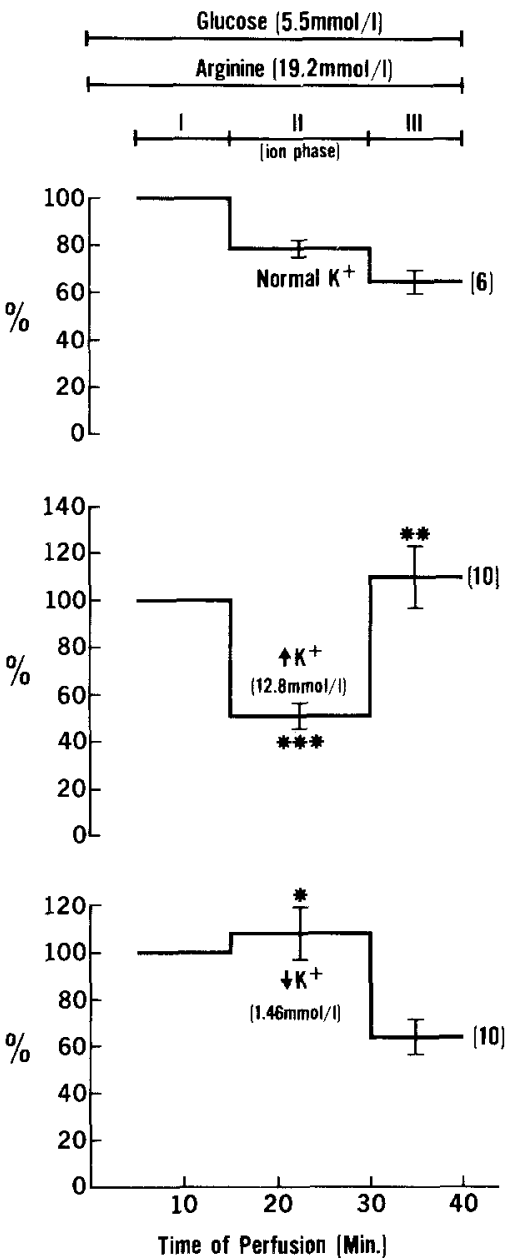

INSULIN
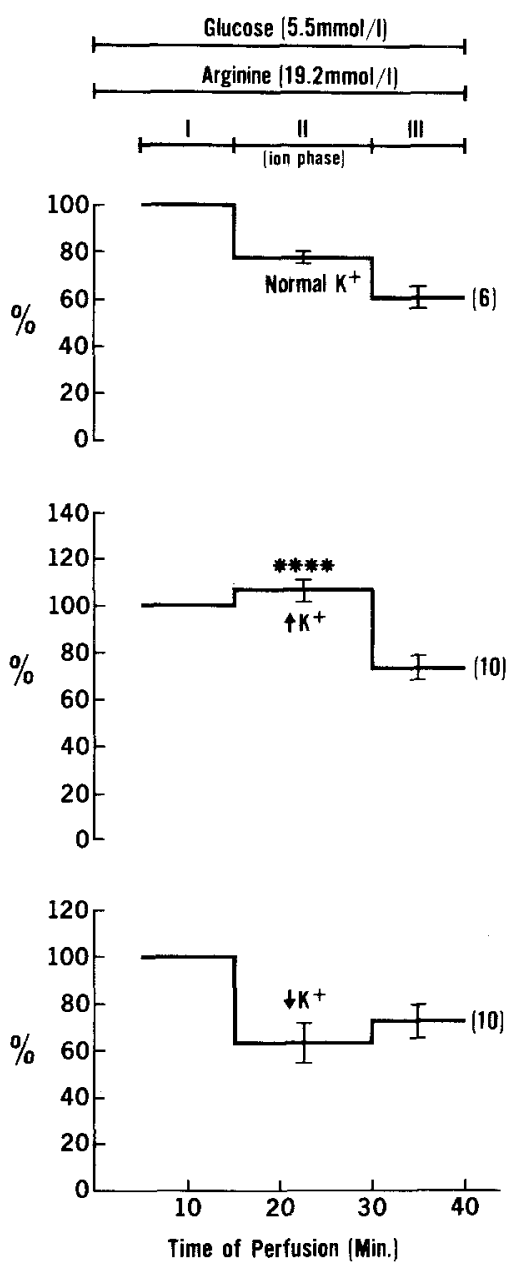

Fig. 1. The effects of high, low or normal (control) potassium ion concentration $\left(\left[\mathrm{K}^{+}\right]\right)$on immunoreactive glucagon (IRG) and immunoreactive insulin (IRI) secretion from normal rat pancreas. Normal $\left[\mathrm{K}^{+}\right]$was maintained during periods I and III; altered $\left[\mathrm{K}^{+}\right]$was introduced during period II. Values expressed represent the mean \pm SEM of the percentage of period I hormone secretion, which has been designated as $100 \%$. Numbers in parentheses represent number of perfusions. Statistical significance for a period was determined relative to its respective period in control perfusions. $* p<0.05$; ** $p<0.02 ; * * * p<0.005 ; * * * * p<0.001$ fornia) and $5.5 \mathrm{mmol} / 1$ glucose. Portal vein effluent was collected continuously in $1 \mathrm{~min}$ fractions into chilled tubes containing $10.5 \mathrm{mg} \mathrm{Na}_{2}$ EDTA and 1,000 KIU Trasylol (FBA Pharmaceuticals, New York). All tubes were centrifuged to remove blood cells, and the supernatants frozen for radioimmunoassay. Insulin was assayed by the double-antibody methed of Morgan and Lazarow [7] with an assay sensitivity of $3 \mathrm{mU} / 1$ and interassay coefficient of variation of $4.8 \%$. Glucagon was assayed by the method of Unger et al. [8], using $30 \mathrm{~K}$ antiserum. Glucagon measurenients were sensitive to $0.02 \mathrm{ng} / \mathrm{ml}$ with an interassay coefficient of variation of $6.1 \%$.

Acute diabetes was induced in 22 animals by IV injection of streptozotocin $(85 \mathrm{mg} / \mathrm{kg}$; Calbiochem, La Jolla, California) $90 \mathrm{~min}$ before isolation and perfusion of the pancreas. Streptozotocin was dissolved in $0.3 \mathrm{ml}$ citrate buffer ( $\mathrm{pH} 4$ ) immediately before use.

Each perfusion included a 10 -min washout period prior to stimulation with $\mathrm{L}$-arginine hydrochloride (19.2 mmol/1; Sigma). Arginine stimulation resulted in typical biphasic patterns of hormone release, the first phase lasting $5 \mathrm{~min}$, and the second phase extending through the duration of each perfusion. Studies were conducted during the second phase of arginine-stimulated hormone release, and were divided into three consecutive periods: the first and third periods, each of $10 \mathrm{~min}$ duration, consisted of normal $\left[\mathrm{K}^{+}\right]$ ( $7.15 \mathrm{mmol} / \mathrm{l})$. During the second period $(15 \mathrm{~min})$, either high or low $\left[\mathrm{K}^{+}\right](12.84$ or $1.46 \mathrm{mmol} / \mathrm{l})$ was introduced by the addition or deletion of potassium chloride. Appropriate adjustments in sodium chloride concentration were made to ensure isotonicity. In control perfusions, normal $\left[\mathrm{K}^{+}\right]$was maintained throughout all three periods.

In some experiments, glucose-free media was used for the entire perfusion: Other experiments utilized an insulin clamp procedure, in which intra-islet concentrations of insulin were approximated through the addition of large doses of crystalline porcine insulin $(20,000 \mathrm{mU} / \mathrm{l}$; Eli Lilly) to the perfusate throughout the three periods of study.

Calculations were made for average hormone secretion during each study period. These values were expressed in terms of the percent of period-I hormone secretion, which was designated as $100 \%$ The mean and SEM were calculated and significance determined by means of the ' $t$ ' test for grouped data.

\section{Results}

The effects of high, low or normal (control) $\left[\mathrm{K}^{+}\right]$on immunoreactive insulin (IRI) and immunoreactive glucagon (IRG) secretion from normal rat pancreas are summarized in Figure 1. Each perfusion showed the classic biphasic response of IRI and IRG to an ar- 
ginine stimulus (data not shown). Following the addition of high $\left[\mathrm{K}^{+}\right]$(ten perfusions), IRI secretion was further enhanced $(p<0.001)$, while IRG secretion was significantly depressed $(p<0.005)$ in comparison with control studies (six perfusions). When normal $\left[\mathrm{K}^{+}\right]$was restored, these changes in hormone secretion were reversed, with IRG secretion exceeding control levels $(p<0.02)$. Introduction of low $\left[\mathrm{K}^{+}\right]$ (ten perfusions), on the other hand, caused a decrease in IRI secretion (NS) and an elevation in the IRG secretion $(p<0.05)$, changes which were again reversed following restoration of normal $\left[\mathrm{K}^{+}\right]$. When interperiod changes in IRI secretion from these two protocols were plotted against corresponding changes in IRG secretion (Fig. $2 \mathrm{~A}$ ), a significant negative correlation was obtained $(p<0.001)$, suggesting the possibility that one of these hormones may act within the islet to influence the secretion of the other.

The above studies were repeated using a second group of 22 animals made acutely diabetic with streptozotocin $90 \mathrm{~min}$ before perfusion. IRI secretion, although greatly suppressed, was not entirely abolished in these studies and displayed early spike responses to both arginine and high $\left[\mathrm{K}^{+}\right]$stimuli. These responses, however, were not sustained and became less marked with increasing time of perfusion (data not shown). Arginine-stimulated IRG secretion, on the other hand, was enhanced over levels observed in normal pancreas. Average period-I IRG secretion from the pancreas of 22 diabetic rats was $2.13 \pm 0.22$ versus $1.31 \pm 0.19 \mathrm{ng} / \mathrm{ml}$ in the pancreas of 23 normal animals $(p<0.01)$. As with normal pancreas, IRG in diabetic pancreas (Fig. 3 A) was inhibited with high $\left[\mathrm{K}^{+}\right](11$ perfusions; $p<0.001)$ and stimulated with low $\left[\mathrm{K}^{+}\right]$(seven perfusions; $p<0.001$ ). These changes, however, were significantly greater on a percentage basis than those observed in normal pancreas ( $p<0.001$ and $p<0.02$, respectively). Restoration of normal $\left[\mathrm{K}^{+}\right]$again caused reversal of these changes in IRG secretion.

When inter-period changes in IRI secretion from diabetic pancreas perfused with high $\left[\mathrm{K}^{+}\right]$were plotted against corresponding changes in IRG secretion (Fig.2B), a significant negative correlation $(p<0.001)$ was again observed. The slope of the line was not significantly different from that obtained in perfusions of normal pancreas (Fig. 2A). When these same inter-period changes in the diabetic pancreas were plotted using data from the low $\left[\mathrm{K}^{+}\right]$protocol, however, no correlation between changes in insulin and glucagon secretion was evident (Fig. 2C), reflecting the absence of an insulin response in these experiments. These findings indicate that elevations in IRG induced by low $\left[\mathrm{K}^{+}\right]$can occur independently of concurrent changes in insulin secretion.

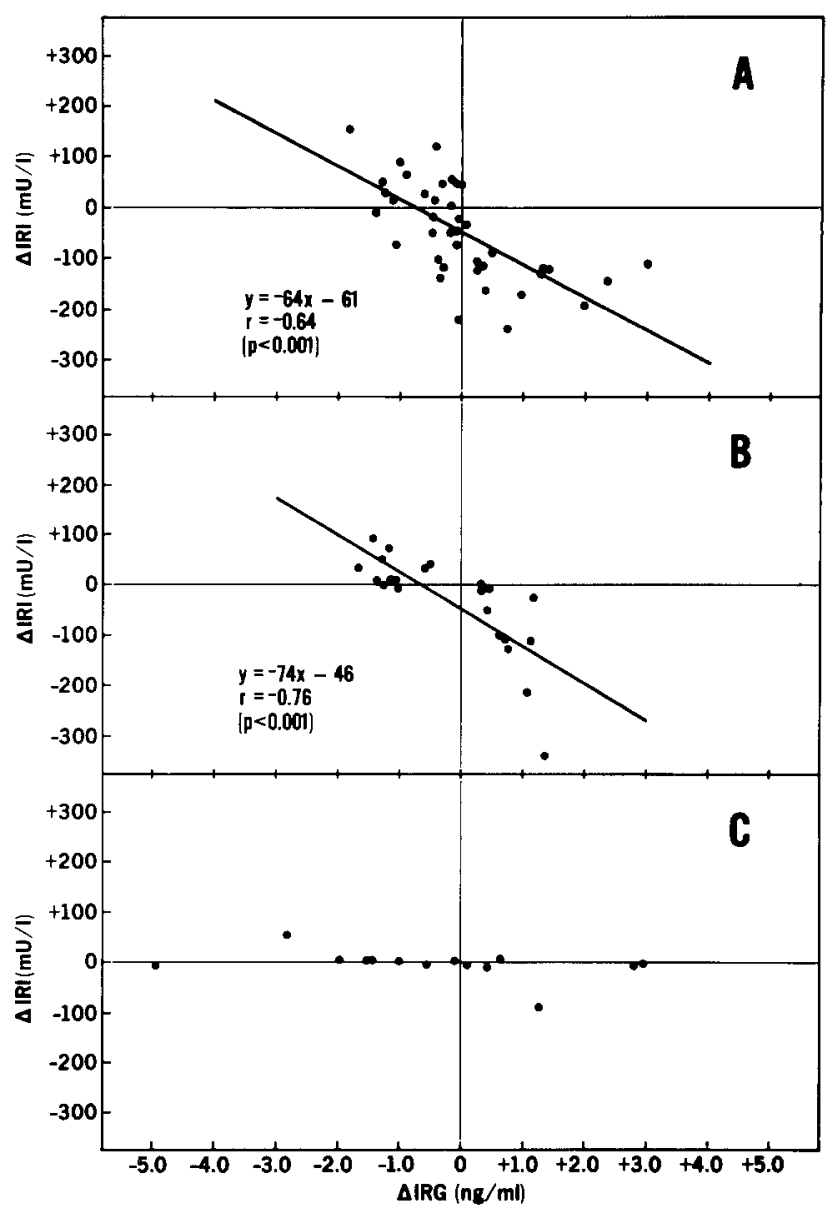

Fig. 2. Inter-period changes in IRI and IRG associated with alterations of $\left[\mathrm{K}^{+}\right]$. Changes in mean IRG secretion (abscissa) are plotted against concurrent changes in mean IRI secretion (ordinate). Plot A represents data from perfusions of normal pancreas exposed to high and low $\left[\mathrm{K}^{+}\right]$. Also shown are data from acute streptozotocindiabetic pancreas, perfused with high $\left[\mathrm{K}^{+}\right]$(plot $\mathrm{B}$ ) or low $\left[\mathrm{K}^{+}\right]$ (plot C). Slopes of lines and $r$ values were determined using linear regression analysis

To provide an additional means of suppressing IRI secretion, glucose-free media was employed in a third set of experiments using pancreas from normal animals. As in diabetic pancreas, IRI secretion with glucose-free perfusate was greatly suppressed, but not entirely abolished. Responsiveness to arginine stimulation was absent, although increased IRI secretion still occurred in response to relative increases in $\left[\mathrm{K}^{+}\right]$ (data not shown). IRG secretion, as in diabetic pancreas, was enhanced in response to arginine stimulation. Average period-I IRG secretion in 16 glucose-free perfusions was $1.97 \pm 0.24$ versus $1.31 \pm 0.19 \mathrm{ng} / \mathrm{ml}$ in the pancreas from 23 normal rats perfused with $5.5 \mathrm{mmol} / 1$ glucose $(p<0.05)$. As with normal and diabetic pancreas, elevated $\left[\mathrm{K}^{+}\right]$in glucose-free perfusate (Fig. 3 B) caused decreased IRG secretion (six perfusions; $p<0.01$ ), while re- 


\section{GLUCAGON}

A
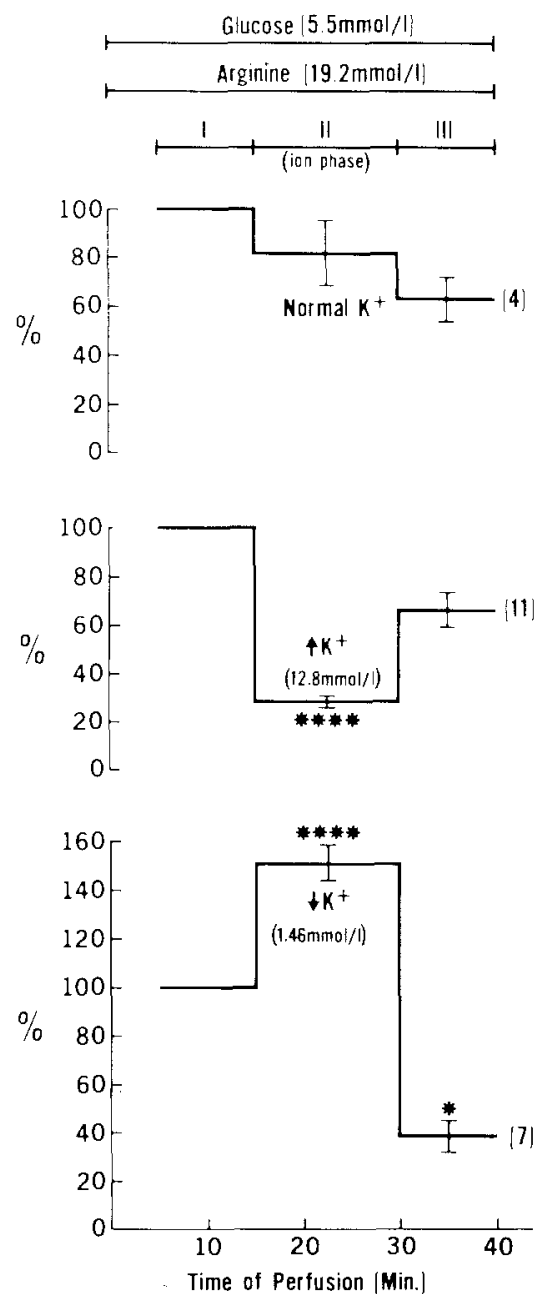

B
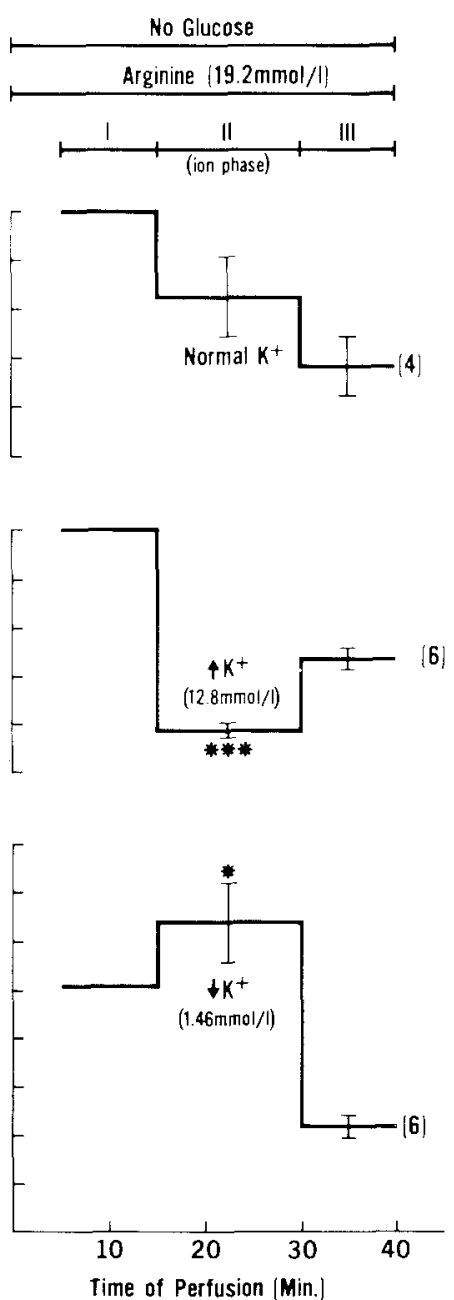

C
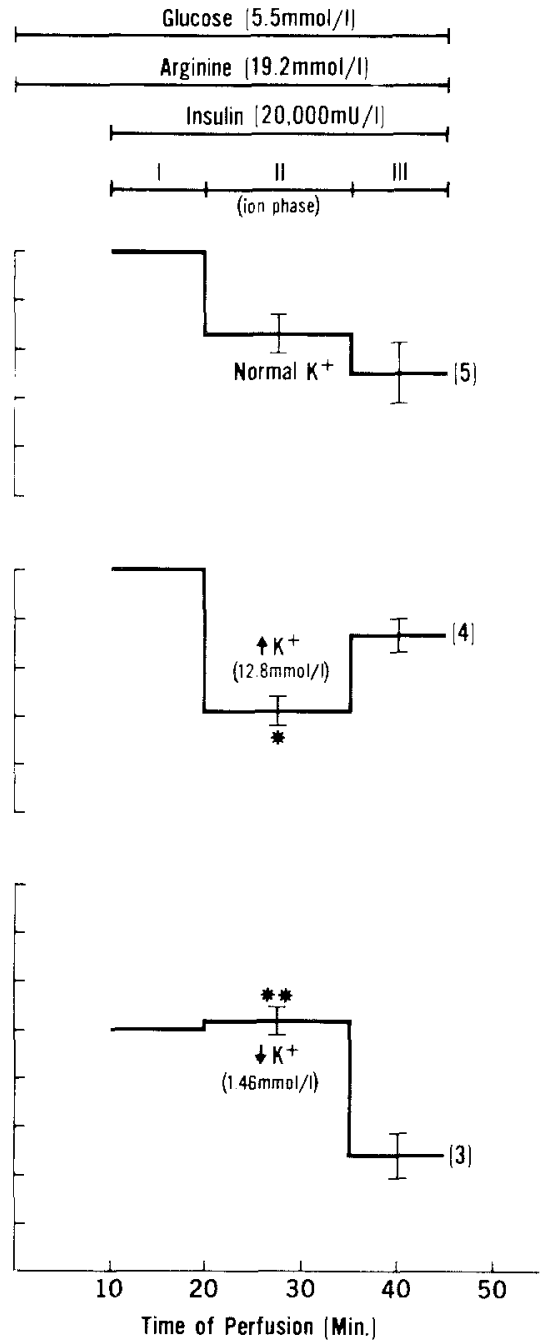

Fig. 3. IRG responses to high, low or normal $\left[\mathrm{K}^{+}\right]$in (A) acutely diabetic rat pancreas, (B) normal pancreas perfused with glucose-free media, and $(C)$ normal pancreas perfused with a pharmacological excess of exogenous insulin. Values expressed represent the mean $\pm S E M$ of the percentage of period I hormone secretion, which has been designated as $100 \%$. Numbers in parentheses represent number of perfusions. Statistical significance for a period was determined relative to its respective period in control perfusions. ${ }^{*} p<0.05 ;{ }^{* *} p<0.02 ;{ }^{* * *} p<0.01$; $* * * * p<0.001$

duced $\left[\mathrm{K}^{+}\right]$resulted in increased IRG secretion (six perfusions; $p<0.05$ ). The magnitude of these effects was similar to that observed in diabetic pancreas. These changes were reversed following restoration of normal $\left[\mathrm{K}^{+}\right]$. When $\left[\mathrm{K}^{+}\right]$was lowered, increased IRG secretion occurred without accompanying changes in IRI secretion, thus providing further evidence that low $\left[\mathrm{K}^{+}\right]$can affect the A cell independent of changes in IRI secretion.

In order to test whether elevated IRI secretion following increased $\left[\mathrm{K}^{+}\right]$is a necessary prerequisite to a fall in IRG secretion, or merely coincidental, an additional series of experiments was conducted in which normal rat pancreas was perfused with buffer containing pharmacological amounts of insulin $(20,000 \mathrm{mU} / 1$; Fig. $3 \mathrm{C})$. It was reasoned that in the presence of an 'insulin clamp', any endogenous changes in IRI secretion resulting from altered $\left[\mathrm{K}^{+}\right]$ would be inconsequential. Representative perfusions are shown in Figure4.

When sustained high concentrations of insulin were added to these perfusions during the second phase of arginine-stimulated hormone secretion, no effect on IRG secretion was noted (12 perfusions). Furthermore, the inhibitory effects of high $\left[\mathrm{K}^{+}\right]$(four perfusions) on IRG secretion were retained 


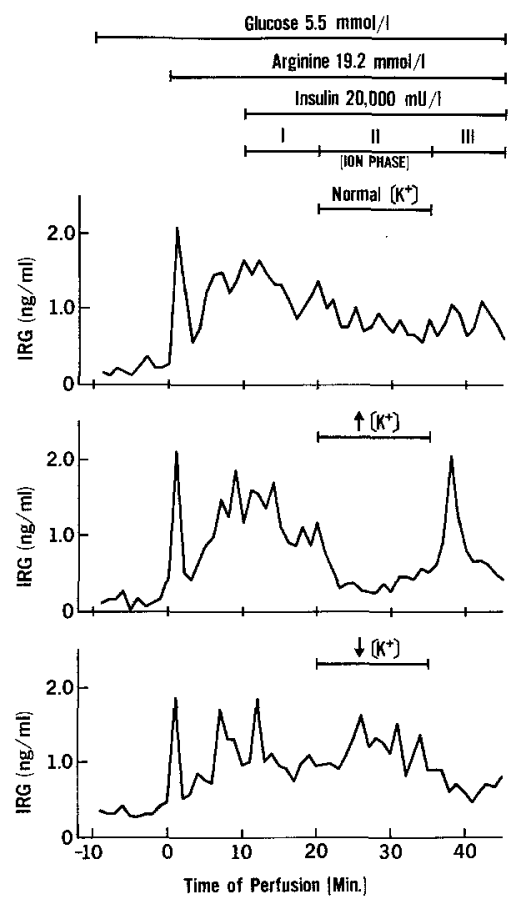

Fig.4. Representative perfusions showing the effects of high $(12.86 \mathrm{mmol} / 1)$, low $(1.46 \mathrm{mmol} / 1)$ or normal $(7.15 \mathrm{mmol} / 1)\left[\mathrm{K}^{+}\right]$on IRG release from normal rat pancreas perfused throughout all three study periods with a pharmacological excess of exogenous insulin

$(p<0.05)$ in the presence of this insulin clamp, as were the stimulatory effects of low $\left[\mathrm{K}^{+}\right]$(three perfusions; $p<0.02$ ). The magnitude of these effects was similar to that observed in normal pancreas without exogenous insulin (Fig. 1). As in previous experiments, changes in IRG secretion were reversed following restoration of normal $\left[\mathrm{K}^{+}\right]$. These studies show that elevated $\left[\mathrm{K}^{+}\right]$remains inhibitory to IRG secretion, even in the presence of a pharmacological excess of insulin.

\section{Discussion}

In our studies in normal pancreas perfused with arginine and either high or low $\left[\mathrm{K}^{+}\right]$, we have observed a significant negative correlation $(p<0.001)$ between changes in IRI secretion and concurrent changes in IRG secretion. The observed elevation of insulin and suppression of glucagon in response to high $\left[\mathrm{K}^{+}\right]$has been reported by us previously [3]; the reverse effect obtained with low $\left[\mathrm{K}^{+}\right]$is now reported for the first time. While correlation data, such as we have obtained, may be consistent with the hypothesized intraislet regulation of glucagon secretion by insulin [9], the data alone are not sufficient to establish such a relationship. In fact, such a mechanism does not appear to be well supported either in the literature or by our findings.

In experiments with tolbutamide, Laube et al. [10] showed that this drug suppressed glucagon secretion uniformly, despite conditions resulting in both high or low insulin levels. Similarly, Grodsky et al. [11] showed that tolbutamide inhibits arginine-stimulated glucagon secretion in the presence or absence of concurrent insulin secretion. In addition, they showed that pharmacological levels of insulin, alone, have no effect on arginine-stimulated glucagon release, in agreement with our own observations. These groups have concluded that tolbutamide blocks glucagon secretion by a mechanism independent of the functional state of the B cell.

Matschinsky et al. have shown that intracellular glucose, ATP, lactate, and cyclic AMP levels in A cells from chronically diabetic versus normal islets cannot account for the observed glucose refractoriness of A cells within diabetic islets [12], and that glucose uptake into islet cells is not significantly modified by insulin [13]. Also, using acute alloxan perfusions of rat pancreas, this group demonstrated that A cell suppression by glucose still occurs, even after the B cell response to glucose is completely inhibited [14]. It would thus appear that the A cell can respond to both glucose and tolbutamide independently of concurrent changes in insulin secretion.

Our data indicate that potassium ion also affects the A cell independently of changes in insulin secretion. In both diabetic and normal pancreas perfused with glucose-free media, we were able to demonstrate significant stimulation of IRG secretion by low $\left[\mathrm{K}^{+}\right]$ when changes in insulin secretion were totally abolished. Conversely, we found that IRG secretion was still inhibited by increased $\left[\mathrm{K}^{+}\right]$under conditions where changes in endogenous IRI secretion were rendered insignificant by the presence of very high levels of exogenous insulin (insulin clamp studies), or when changes in IRI secretion were greatly reduced (diabetic pancreas). This latter observation is in agreement with the findings of Epstein et al. [4]. Together, these findings point to either a direct effect of potassium ion on the A cell, or an indirect effect mediated through an agent other than insulin.

This is not meant to imply that insulin is without effect on IRG secretion. On the contrary, we have noted greatly enhanced levels of arginine-stimulated IRG secretion from both diabetic pancreas and pancreas perfused with glucose-free media, in which IRI secretion was greatly suppressed. The responsiveness of IRG to changes in $\left[\mathrm{K}^{+}\right]$in these protocols was also markedly exaggerated in comparison to normal pancreas, or pancreas perfused with excess exogenous insulin. Thus, it can be said that the presence or absence 
of insulin secretion appears to affect the amplitude of induced changes in IRG secretion, but not the qualitative nature (direction) of these changes. When the secretion of endogenous insulin was not suppressed, however, the addition of excess exogenous insulin (insulin clamp experiments) was without effect on arginine-stimulated glucagon release.

If it is true, as Epstein et al. have suggested [4, 11], that the direct effect of increased $\left[\mathrm{K}^{+}\right]$is to depolarize the A cell and cause elevated IRG secretion, then how does one account for the opposite effect in the arginine-stimulated pancreas? These authors have attempted to explain this as being the result of excessive depolarization of the A cell, resulting in an over-accumulation of intracellular calcium ion. The latter has been reported to cause inhibition, rather than stimulation of hormone secretion [15]. Our laboratory, however, has previously shown that the addition of high calcium ion levels to the arginine-stimulated pancreas causes further stimulation, rather than inhibition, of both IRI and IRG secretion [3].

We believe it is more likely that potassium ion changes are exerting an indirect effect on the argininestimulated A cell. Our studies have essentially ruled out insulin as the paracrine mediator of such an indirect effect, leaving other islet hormones, notably somatostatin, as likely candidates for this role. Studies are currently underway to clarify these relationships.

Acknowledgements. We gratefully acknowledge the assistance of Ms. C. Parsons in preparing this manuscript. This work was supported by the Veterans Administration, and National Institutes of Health Grant R01-AM-19610.

\section{References}

1. Rowe JW, Tobin JD, Rosa RM, Andres R (1980) Effect of experimental potassium deficiency on glucose and insulin metabolism. Metabolism 29: 498-502

2. Grodsky GM, Bennett LL (1966) Cation requirements for insulin secretion in isolated perfused pancreas. Diabetes 15: 910-913
3. Bhathena SJ, Perrino PV, Voyles NR, Smith SS, Wilkins SD, Coy DH, Schally AV, Recant L (1976) Reversal of somatostatin inhibition of insulin and glucagon secretion. Diabetes 25 : $1031-1040$

4. Epstein G, Fanska R, Grodsky GM (1978) The effect of potassium and valinomycin on insulin and glucagon secretion in the perfused rat pancreas. Endocrinology 103:2207-2215

5. Hales CN, Milner RDG (1968) The role of sodium and potassium in insulin secretion from rabbit pancreas. J Physiol 194: $725-743$

6. Curry DL, Bennett LL, Grodsky GM (1968) Dynamics of insulin secretion by the perfused rat pancreas. Endocrinology 83 : $572-584$

7. Morgan CR, Lazarow A (1963) Immunoassay of insulin: Two antibody system. Diabetes 12:115-126

8. Unger RH, Eisentraut AM, Madison LL (1963) The effects of total starvation upon the levels of circulating glucagon and insulin in man. J Clin Invest 42; 1031-1039

9. Ostenson CG (1979) Regulation of glucagon release: Effects of insulin on the pancreatic $A_{2}$-cell of the guinea pig. Diabetologia $17: 325-330$

10. Laube H, Fussganger R, Goberna R, Schroder K, Straub K, Sussman K, Pfeiffer EF (1971) Effects of tolbutamide on insulin and glucagon secretion of the isolated perfused rat pancreas. Horm Metab Res 3: 238-242

11. Grodsky GM, Epstein GH, Fanska R, Karam JH (1977) Pancreatic action of the sulphonylureas. Fed Proc 36:2714-2719

12. Matschinsky FM, Pagliara AS, Hover BA, Pace CS, Ferrendelli JA, Williams A (1976) Hormone secretion and glucose metabolism in islets of Langerhans of the isolated perfused pancreas from normal and streptozotocin diabetic rats. J Biol Chem 251: 6053-6061

13. Matschinsky FM, Pagliara AS, Stillings SN, Hover B (1976) Glucose and ATP levels in pancreatic islet tissue of normal and diabetic rats. J Clin Invest 58: 1193-1200

14. Pagliara AS, Stillings SN, Zawalich WS, Williams AD, Matschinsky FM (1977) Glucose and 3-0-methylglucose protection against alloxan poisoning of pancreatic alpha and beta cells. Diabetes 26: 973-979

15. Lundquist I, Fanska R, Grodsky GM (1976) Interaction of calcium and glucose on glucagon secretion. Endocrinology 99 : $1304-1312$

Received: 28 April 1981

and in revised form: 7 August 1981

Dr. S.Smith

Veterans Administration Medical Center

Diabetes Research Laboratory

50 Irving Street NW

Washington, DC 20422, USA 